\title{
ESTIMATING THE EMISSION FACTOR FOR DIFFERENT VEHICLES IN THE CITY OF CARTAGENA DE INDIAS, COLUMBIA
}

\author{
JOSÉ ANTONIO ÁLVAREZ, EDGAR QUIÑONES \& VANESSA ÁLVAREZ \\ GRUPO GIMA Grupo de Investigación para el Medio Ambiente, Universidad de Cartagena, Colombia
}

\begin{abstract}
In recent decades, the scientific community has noted that the pollutants released into atmosphere produced by road traffic is one of the most significant causes in the deterioration of air quality in cities. Therefore, it is important to estimate the emission factors associated with road traffic, which turns out to be the theoretical basis for estimating the emissions of air pollutants in a precise way. The emissions of atmospheric pollutants generated by mobile sources may produce severe impacts on human health because these pollutants are generally produced in areas with a high density of inhabitants and at ground level. The present study aims to estimate the concentration of air pollutants generated by road traffic on the main roads of the city of Cartagena, which were selected while taking into account the critical points of highest traffic congestion. The emission factors for $\mathrm{PM}_{2.5}$, using the inverse modeling technique, were estimated taking into account the average concentrations measured over 24-hour period and the pollutants that represent the greatest threat to public health were determined. This study is a starting point to determine the magnitude of the emissions associated with road traffic in Cartagena, and it also provides technical support to be able to identify in an approximate way the impact of different vehicle sources in the city.
\end{abstract}

Keywords: road traffic, emission factors, inverse modeling technique, pollutant concentrations, air pollutants, public health.

\section{INTRODUCTION}

The increase in concentrations of atmospheric pollutants is a serious environmental problem that requires strategies focused on mitigating the impacts that these pollutants produce on human health and their environment. Despite significant improvements in fuel quality and engine technology, the current urban environment is still dominated by road traffic emissions [1]. The presence of particulate matter, carbon monoxide, photochemical oxidants and sulphur and nitrogen oxides in urban areas are the main liable factors for explaining the air pollution. For this reason, the estimation of the emission factor is an essential element to management policies and control actions that improve the quality of the air breathed by people.

The road traffic emission factors represent the main source of uncertainty when quantifying the emission of gases and particulate matter [2]. In the Colombian Caribbean region many cities have not estimated the emission factors yet, mainly because the necessary economic and technical resources are not available. This fact contributes to the increase in the uncertainty of emissions estimation. The objective of the present study is to determine the average emission factor of the vehicle fleet of Cartagena de Indias, implementing the inverse modeling technique [3], counting with the AERMOD air quality software as support. The inverse application of the dispersion models or inverse modeling technique can be implemented for different urban environments such as closed streets and urban cannons [4][6], open streets or motorways [7]. In this case, the ways with the highest vehicle flow were selected and the upper limit of the emission factor was calculated. 


\section{MATERIALS AND METHODS}

The inverse modelling technique was developed to implement an air quality model which must be calibrated with experimental data recorded through a monitoring campaign. The development of the methodology was carried out through three stages: 1) Selection of the monitoring sites, 2) monitoring campaign (Figs 1 and 3) modelling and estimation of the emission factor [8]. In this case, the pollutant concentrations registered by the monitoring network of pollutants (SVCA) was not considered.

\subsection{Modelling and estimating the emission factor}

To estimate the emission factor the AERMOD air quality model was implemented, which is a steady-state plume model recommended by the US-EPA to estimate contaminant concentrations [9]. This software uses the stationary Gaussian plume model, which incorporates different factors related to the source as well as meteorological factors to estimate the emitted pollutant concentration. Mobile sources were taken into account such as area sources and geographic information was obtained from the Geographic Information System WebGIS SRTM3 [10].

The inverse modeling technique is a novel alternative that implements a combination of pollutant measurements from road traffic and atmospheric dispersion models in urban environments. Through the application of the inverse method it is possible to quantify the

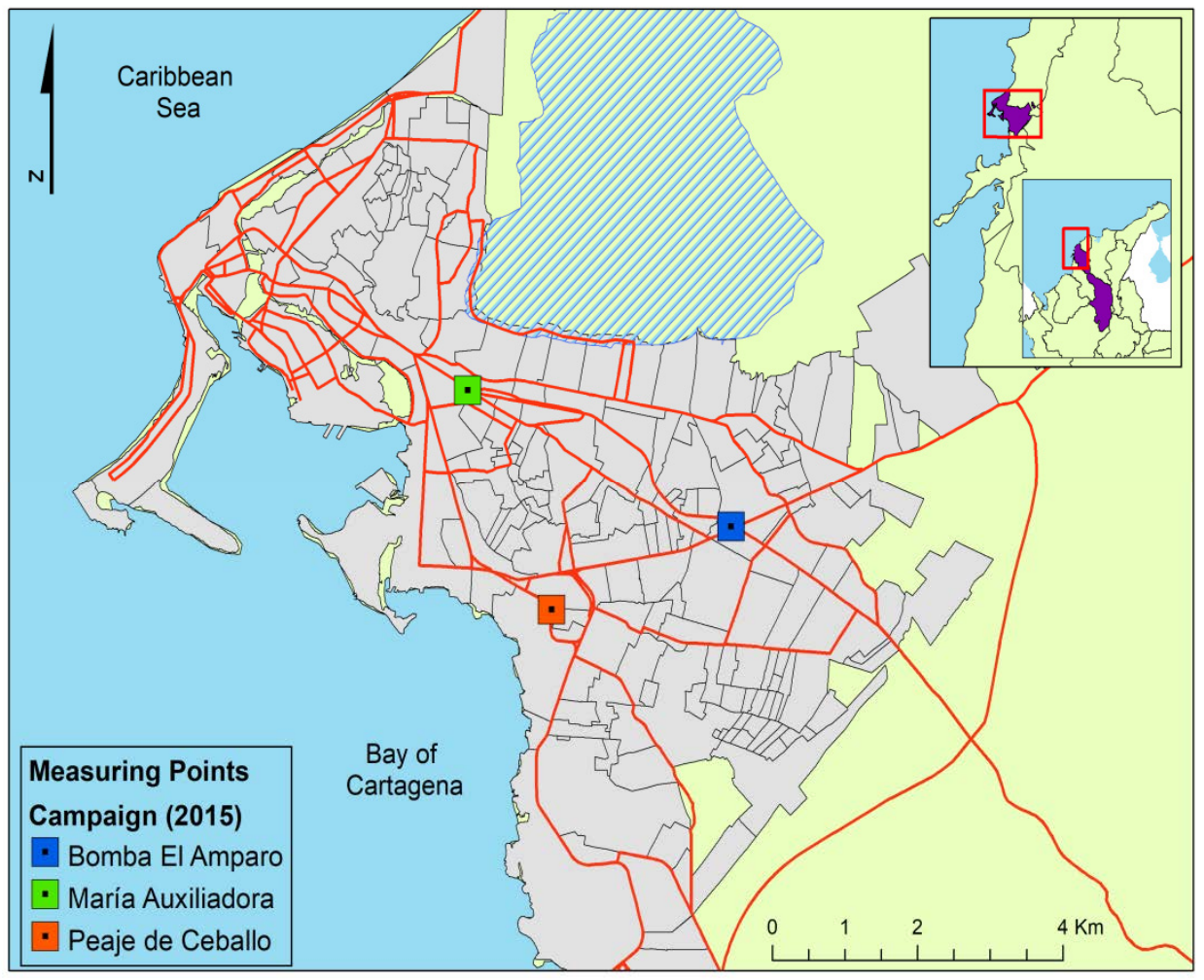

Figure 1: Monitoring campaign (2015) in Cartagena de Indias. (Source: GIMA, 2017.) 
combined effect of the variables that significantly affect the emissions generated by traffic in the city such as the driving conditions of the vehicle, nevertheless it cannot consider the technologies of the combustion engines, the emission control systems, the type and the quality of the used fuel and the vehicles technical status that constitute the motor park of the city.

The relationship between emissions and pollutant concentrations can be established with a dispersion model that describes the predominant physical and chemical processes [11]. The concentrations of pollutants can be related to the phenomena involved in the dispersion and with the emitted quantity of pollutant applying the following general equation:

$$
\mathrm{E}=(\mathrm{EF} \cdot \mathrm{N}) /(\mathrm{T} \cdot \mathrm{c})
$$

- $\quad$ E: Emission $\left(\mathrm{g} / \mathrm{s} \cdot \mathrm{m}^{2}\right)$.

- $\quad$ EF: Emission Factor $(\mathrm{g} / \mathrm{km})$.

- $\mathrm{N}$ : Number (average) of vehicles per day.

- $\mathrm{T}$ : Track width.

- c: Unit conversion factor $86.400\left(\right.$ days $\left.\cdot \mathrm{km}^{2} / \mathrm{m}^{2} \cdot \mathrm{s}\right)$.

When comparing the obtained values by this general equation with the values obtained by modelling so a linear relation is found then the following expression must be applied:

$$
\mathrm{y}=\mathrm{a} \cdot \mathrm{X}_{1}+\mathrm{b} \cdot \mathrm{X}_{2}+\mathrm{C}
$$

By transforming variables, the following results:

$$
\mathrm{E}=\mathrm{a} \cdot \mathrm{V}_{\mathrm{L}}+\mathrm{b} \cdot \mathrm{V}_{\mathrm{H}}+\mathrm{C} \text {. }
$$

- E: Emission.

- $\mathrm{V}_{\mathrm{L}}$ : Light vehicle fleet.

- $\mathrm{V}_{\mathrm{H}}$ : Heavy vehicle fleet.

- a, b: parameters.

It is possible to establish, according to light or heavy vehicles classification, the following proportional relations:

$$
\begin{aligned}
E \cdot v_{l} & =a \cdot V_{L} . \\
E \cdot v_{h} & =b \cdot V_{H} .
\end{aligned}
$$

- E: Emission.

- $\mathrm{v}_{\mathrm{h}} / \mathrm{v}_{\mathrm{l}}$ : heavy vehicles/light vehicles.

Starting from the initial equation, it can be deduced (Ac = activity; number of vehicles divided by track width, T):

$$
\mathrm{E} \cdot \mathrm{V}_{\mathrm{l}}=\mathrm{a} \cdot \mathrm{V}_{\mathrm{L}}=\mathrm{EF} \cdot \mathrm{Ac}=\mathrm{EF} \cdot \mathrm{V}_{\mathrm{L}} / \mathrm{T} .
$$

Therefore, solving from the eqn (6), the emission factor (EF) is calculated as follows:

$$
\mathrm{EF}=\mathrm{a} \cdot \mathrm{T}
$$


Through the application of the linear regression method it has been possible to determine a global emission factor for mobile sources in the city.

The methodology for determining the emission factor is based on the adjustment of the concentrations estimated by the model with the concentrations measured in the monitoring campaign using linear regression, taking into account the data of the concentrations estimated by the model and the estimated emissions found with the general equation as calibration criteria.

Subsequently, the statistical ANOVA analysis was applied for different levels of confidence, and the ranks at which there is a greater probability of finding the real emission factor values were obtained (Fig. 2).

\section{RESULTS}

In order to assess the most unfavourable situation related to the air pollution generated by vehicle traffic the mean concentrations of $\mathrm{CO}$ and $\mathrm{PM}_{2.5}$ were analyzed, for periods between 1 hour and 24 hours, observing the maximum values recorded (Fig. 3). Subsequently, through the software AERMOD, the spatial distribution of the average monthly concentration of pollutants was simulated across the three places under study, observing the influence area of both pollutants. Finally, the emission factor's maximum limits were found generally for light and heavy vehicles, but the emission factors were not found for the different categories of vehicles.

The concentrations of $\mathrm{PM}_{2.5}$ were particularly high, exceeding the established limit by the Colombian air quality standard in the measuring and recording sites across the city (Fig. 3).

Theoretical emissions were estimated taking into account emission factors referenced in the literature and the geometric characteristics of the pathways under study in the three selected sites (Table 1 and Table 2).

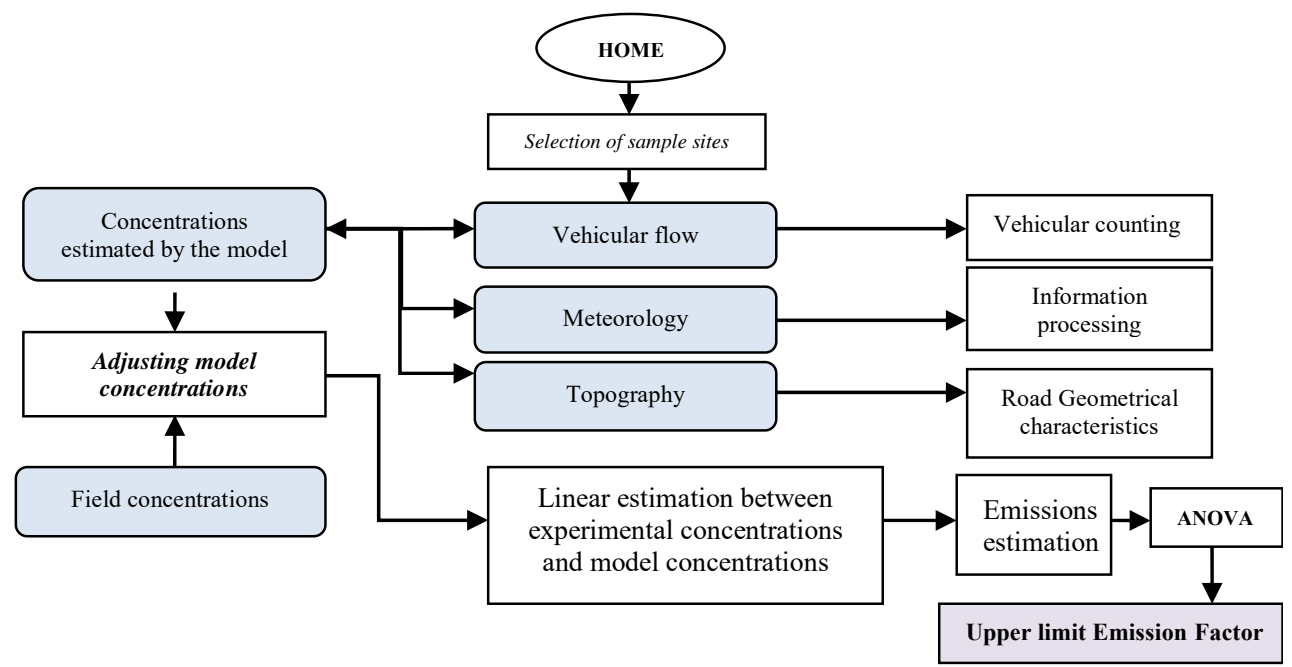

Figure 2: Study methodology. (Source: GIMA, 2016.) 

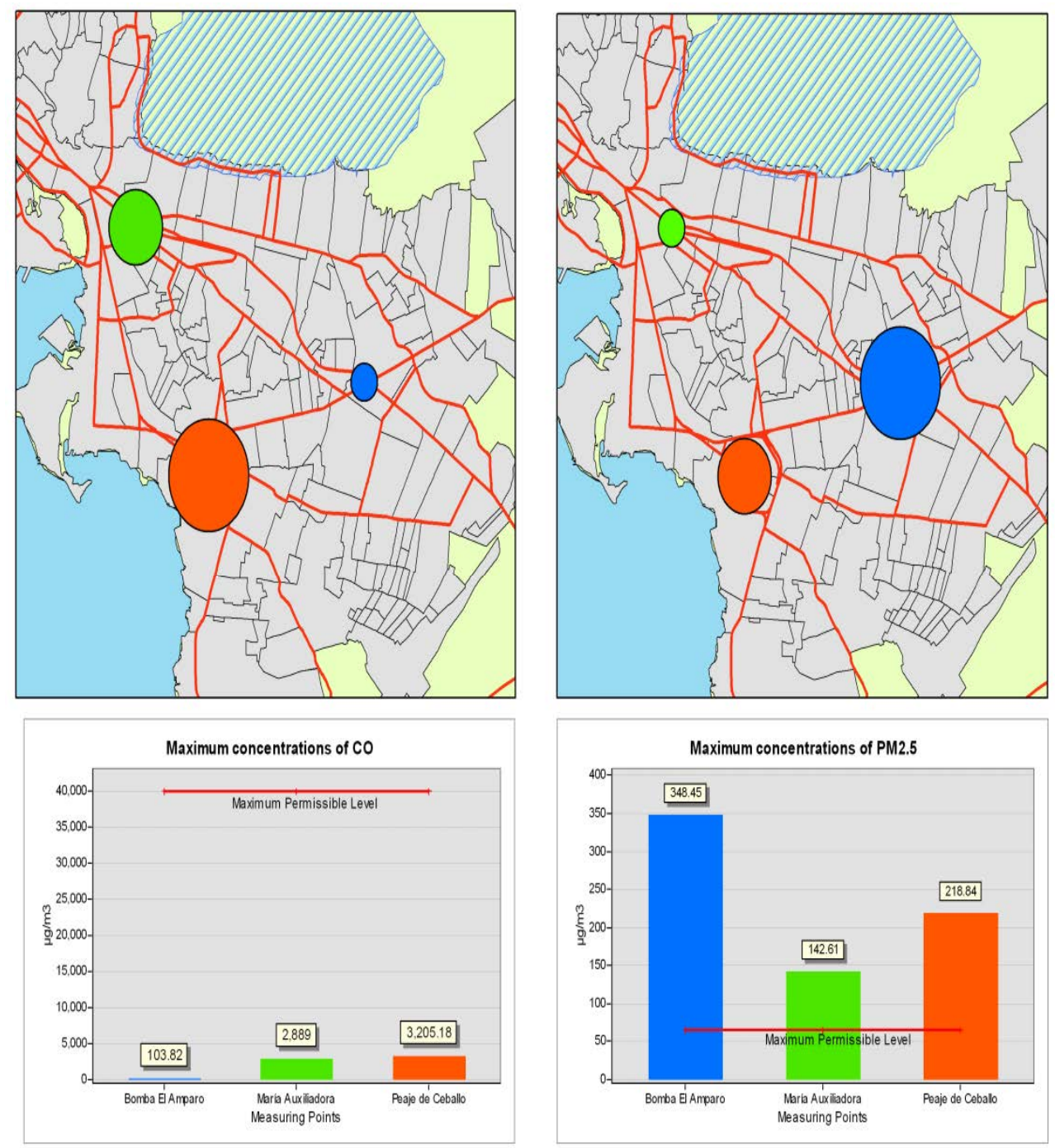

Figure 3: $\mathrm{CO} / \mathrm{PM}_{2.5}$ maximum concentrations $\left(\mu \mathrm{g} / \mathrm{m}^{3}\right)$. (Source: GIMA, 2016.)

Table 1: Geometric characteristics of the pathways. (Source: GIMA, 2016.)

\begin{tabular}{|l|c|c|}
\hline \multicolumn{1}{|c|}{ Sector } & Track width (m) & Strip length (m) \\
\hline Bomba El Amparo & 6 & 60 \\
\hline María Auxiliadora & 7.7 & 170 \\
\hline Peaje de Ceballo & 13.5 & 45.15 \\
\hline
\end{tabular}


Table 2: Estimated theoretical emissions across the sampling sites. (Source: GIMA, 2016.)

\begin{tabular}{|c|c|c|c|}
\hline Sectors & Bomba El Amparo & María Auxiliadora & Peaje de Ceballo \\
\hline Initial emission & $2.6818 \mathrm{E}-05$ & $1.1299 \mathrm{E}-05$ & 0.00013007 \\
\hline $10.00 \%$ & $2.95 \mathrm{E}-05$ & $1.2429 \mathrm{E}-05$ & 0.00014308 \\
\hline $30.00 \%$ & $3.4864 \mathrm{E}-05$ & $1.4689 \mathrm{E}-05$ & 0.0001691 \\
\hline $50.00 \%$ & $4.0228 \mathrm{E}-05$ & $1.6949 \mathrm{E}-05$ & 0.00019511 \\
\hline $70.00 \%$ & $4.5591 \mathrm{E}-05$ & $1.9209 \mathrm{E}-05$ & 0.00022113 \\
\hline $100.00 \%$ & $5.3637 \mathrm{E}-05$ & $2.2599 \mathrm{E}-05$ & 0.00026015 \\
\hline
\end{tabular}

According to the information available for this research the model AERMOD View was selected because it is suitable to represent the transport of the $\mathrm{PM}_{2.5}, \mathrm{CO}$ and the concentrations that could be present in the study sites depending on the emissions of pollutants emitted from the mobile sources. The time concentrations estimated by the model were found according to the emissions of every source and taking into account the meteorology of the months in which the measurement campaign was carried out.

The model results are represented on a mesh of receptors, showing the isoconcentration curves for the maximum level of concentration of the considered pollutant (Fig. 4).

In this case, only the $\mathrm{PM}_{2.5}$ was considered because it exceeded the legal limits recommended by the regulation.

By representing the percentage values of increase in the theoretical emissions and relating them with the percentage values of increase of the concentrations estimated with the model AERMOD it was found that the relationship is fundamentally linear, resulting in a similar behavior across the three sampling sites (Fig. 5).
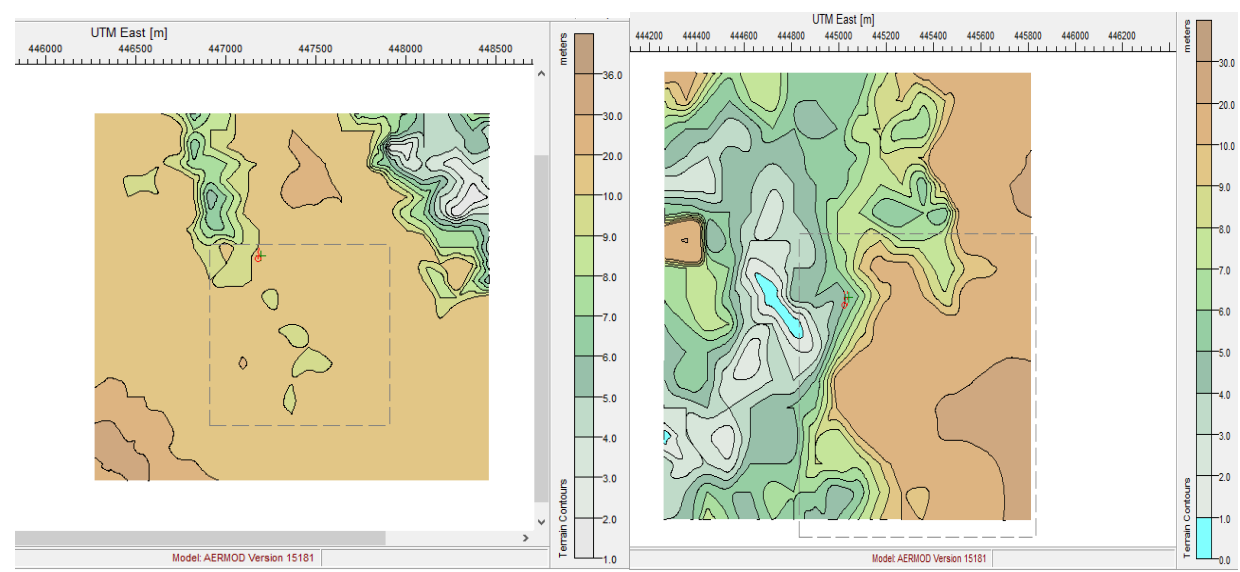

Figure 4: $\quad \mathrm{PM}_{2.5}$ isoconcentration curves projected for the sectors Bomba de El Amparo (left) and Peaje de Ceballo (right). (Source: Own elaboration with AERMOD VIEW.) 


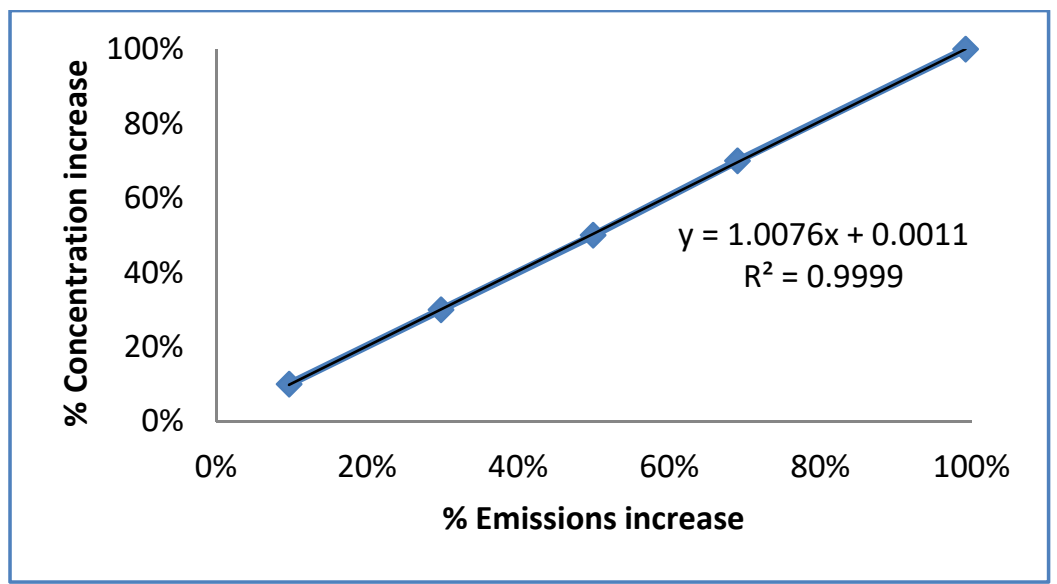

Figure 5: Increase of concentration proportional to the increase of the emission in the Sector Bomba de El Amparo. (Source: GIMA, 2016.)

According to the behavior experienced between the variables, in the sampling sites, the daily emission by vehicle count was estimated applying the linear regression for the theoretical emissions and the concentrations estimated by the model.

The calculated emissions with the general eqn (1) were related to the average of counted vehicles per hour and day (Table 3).

The emission values were grouped into two categories: light vehicles and heavy vehicles (Table 4). In the category of light vehicles cars and motorcycles were classified, and in the category of heavy vehicles vans, buses and greatest displacement vehicles.

Table 3: Emissions calculated by linear regression in the sector Bomba de El Amparo. (Source: GIMA, 2016.)

\begin{tabular}{|c|c|c|c|c|}
\hline $\begin{array}{c}\text { Emission } \\
\mathrm{g} / \mathrm{seg} \cdot \mathrm{m}^{2}\end{array}$ & Cars & Buses & Heavy vehicles & Motorcycle \\
\hline $1.43 \mathrm{E}-03$ & 538 & 44 & 57 & 16 \\
\hline $2.09 \mathrm{E}-03$ & 524 & 66 & 36 & 728 \\
\hline $2.09 \mathrm{E}-03$ & 526 & 67 & 41 & 680 \\
\hline $2.78 \mathrm{E}-03$ & 483 & 53 & 18 & 468 \\
\hline
\end{tabular}

Table 4: Emissions calculated by linear regression in the sector Bomba de El Amparo. (Source: GIMA, 2016.)

\begin{tabular}{|c|c|c|}
\hline $\begin{array}{c}\text { Emission } \\
\mathrm{g} / \text { hour } \cdot \mathrm{m}^{2}\end{array}$ & Light vehicles $(\mathrm{veh} / \mathrm{h})$ & Heavy vehicles (veh/h) \\
\hline $5.15 \mathrm{E}+00$ & 554 & 101 \\
\hline $7.52 \mathrm{E}+00$ & 1252 & 102 \\
\hline $7.52 \mathrm{E}+00$ & 1206 & 108 \\
\hline $1.00 \mathrm{E}+01$ & 951 & 71 \\
\hline
\end{tabular}


Finally, the maximum values of the emission factors were calculated for each one of the measuring sites (Table 5). It should be taken into account that the values provided by the literature have a degree of uncertainty, and therefore it is recommended to establish a range of values at which the real value of the emission factor is most likely to be found. It can be deduced that the values differ significantly across each sector, probably due to the influence of different fixed sources close to the stations of measurement.

The confidence levels in the sectors of Bomba de El Amparo and Peaje de Ceballo were established at $88 \%$, while for the sector Maria Auxiliadora was established at $90 \%$. The analysis shows that despite the fact that the transport by wind is a significant contribution of $\mathrm{PM}_{2.5}$ on urban roads in the city, the vehicle's mechanical action contributes the most significant emission. It is noted that the emission factor's highest value was presented in the Peaje de Ceballo sector $(740 \mathrm{~g} / \mathrm{km}$ veh), probably due to concentrations that did not only correspond to the vehicular traffic but also to the pollutants produced across the large number of existing stationary sources around the receiver.

The emission factor of mobile sources obtained for the city of Cartagena de Indias were compared with those obtained in other international investigations (Table 6).

\section{CONCLUSIONS}

The estimation of air pollutant concentrations by implementing the AERMOD software allowed us to define the vehicular traffic impact on the air quality of areas near the roads under study. It was possible to estimate the degree of concentration of pollutants that transport emissions contribute to the total pollution existing in these areas, demonstrating the effectiveness of the tool in the calculation of concentrations and dispersion of pollutants.

The average monthly spatial representation of two important atmospheric pollutants generated mainly by vehicular traffic was carried out by identifying greatest impact areas in the vicinity of the selected roads. This fact will allow the extrapolation of the application of

Table 5: Estimated emission factors upper limits ( $\mathrm{g} / \mathrm{km}$ veh) for $\mathrm{PM}_{2.5}$. (Source: GIMA, 2016.)

\begin{tabular}{cccc}
\hline Categories & Bomba El Amparo & $\begin{array}{c}\text { Sector María } \\
\text { Auxiliadora }\end{array}$ & $\begin{array}{c}\text { Sector Peaje de } \\
\text { Ceballo }\end{array}$ \\
\hline Light vehicles & 57 & 28 & 102 \\
Heavy vehicles & 14 & 77 & 740 \\
\hline
\end{tabular}

Table 6: Estimated Emission Factors for Cartagena and its comparison with other international studies (g/km veh). (Source: GIMA, 2016.)

\begin{tabular}{|c|c|c|c|c|c|}
\hline City & \multicolumn{2}{|c|}{$\mathrm{CO}$} & \multicolumn{2}{|c|}{$\mathrm{PM}_{2.5}$} & Source \\
\hline & Light & Heavy & Light & Heavy & \multirow[b]{2}{*}{ Present study } \\
\hline Cartagena & - & $42 \pm 1.96$ & $57 \pm 1.96$ & $14 \pm 1.96$ & \\
\hline Bogotá & $8.27 \pm 1.96$ & $385.2 \pm 142.3$ & $0.27 \pm 0.08$ & $2.38 \pm 0.08$ & $\begin{array}{c}\text { (Tarapues, } \\
\text { 2003) }\end{array}$ \\
\hline $\begin{array}{l}\text { Santiago de } \\
\text { Chile }\end{array}$ & $3.5 \pm 3.90$ & $28.2 \pm 15.2$ & ---- & ---- & $\begin{array}{l}\text { (Olcese, } \\
\text { 2001) }\end{array}$ \\
\hline Copenhague & \multicolumn{2}{|c|}{$11.0 \pm 2.0$} & ----- & ----- & $\begin{array}{c}\text { (Gramotnev, } \\
2003)\end{array}$ \\
\hline
\end{tabular}


the inverse methodology in ways of similar characteristics, in order to evaluate the residential and population sectors that are affected by the emission of pollutants from vehicular traffic. The emission factor values estimated in different cities all around the world are in the range obtained in the present investigation.

In Cartagena there is no emissions inventory that provides detailed information on the fixed sources and the characteristics of the mobile sources, therefore it is difficult to know more accurately the amounts of pollutants emitted by the different emitting agents. In this regard, as a recommendation, the creation of a single format for registration of emissions is considered, created by all the industries that have sources of pollutants in their different processes, as well as the incorporation of qualified personnel to control the records.

In reference to mobile sources, detailed technical information is required from the different vehicle classes as well as the general characteristics of the vehicle fleet as a whole. The high estimated emission factor value corresponding to Peaje de Ceballo $(740 \mathrm{~g} / \mathrm{km}) \mathrm{can}$ be explained by the numerous loading docks for vehicles and industries surrounding the measuring station and which would contribute significantly to the high registered particle values.

The particles that come from the gasoline's combustion, or diesel, are generally fine or ultrafine $\left(\mathrm{PM}_{0.1}\right.$ and $\left.\mathrm{PM}_{2.5}\right)$, with a composite core of carbon and a large area of its surface that facilitate the union of countless substances such us metallic compounds, allergens, volatile organic compounds and other types of particles with which they can form aggregates with high irritant potential. This pollutant, which is highly detrimental to people's health, has high concentrations in the areas of major vehicle traffic in the city, affecting the health of pedestrians and residents, but especially affecting the vulnerable groups such as children, pregnant women or the elderly.

For this reason, a study in the district that links the concentrations of $\mathrm{PM}_{2.5}$ with the different cardiorespiratory diseases caused by inhalation of this pollutant would be especially useful.

\section{ACKNOWLEDGEMENTS}

The authors thank the Universidad de Cartagena, the Universidad Tecnológica de Bolívar and COLCIENCIAS for their academic support to the development of this study.

"ELARCH project: Reference number 552129-EM-1-2014-1-IT-ERA MUNDUSEMA21 funded with support of the European Commission. This document reflects the view only of the author, and the Commission cannot be held responsible for any use which may be made of the information contained therein."

\section{REFERENCES}

[1] Fenger, J., Urban air quality. Atmospheric Environment, 33(29), pp. 4877-4900, 1999.

[2] Belalcazar, L., Clappier, A., Nadège, B., Flassak, T. \& Eichhorn, J., An evaluation of the estimation of road traffic emission factors from tracer studies. Atmospheric Environment, 44(31), pp. 3814-3822, 2010.

[3] Manzi, V., Belalcazar, L., Giraldo, E., Zarate, E. \& Clappier, A., Estimación de los factores de emisión de las fuentes móviles de la ciudad de Bogotá. Revista de Ingeniería, 18, pp. 18-25, 2003.

[4] Olcese, L., Palancar, G. \& Toselli, B., An inexpensive method to estimate CO and $\mathrm{NO}_{\mathrm{X}}$ from mobile sources. Atmospheric Environment, 35, pp. 6213-6218, 2001.

[5] Ziv, A., Berkowicz, R., Yakovleva, E., Genikhovich, E. \& Palmgren, F., Analysis of the St. Petersburg traffic data using the OSPM model. Water, Air and Soil Pollution: Focus, 2(5), pp. 297-310, 2002. 
[6] Palmgren, F., Berkowicz, R., Ziv, A. \& Hertel, O., Actual car fleet estimated from urban air quality measurements and street pollution models. The Science of the Total Environment, 235, pp. 101-109, 1999.

[7] Gramotnev, G., Brown, R., Ristovski, Z., Loveday, J. \& Morawska, L., Determination of average emission factors for vehicles on a busy road. Atmospheric Environment, 37(4), pp. 465-474, 2003.

[8] Álvarez Vanessa, E., Personal communication, 25 Sep. 2015, Master of Science. Análisis estadístico de la incidencia de las emisiones del tráfico vehicular en la calidad del aire de la ciudad de Cartagena, Universidad de Cartagena, Cartagena de Indias, Colombia.

[9] United States Environmental Protection Agency (USEPA). Support Center for Regulatory Atmospheric Modeling (SCRAM). https://www.epa.gov/scram/airquality-dispersion-modeling-preferred-and-recommended-models. Accessed on: 22 Dec. 2017.

[10] WebGIS. http://www.webgis.com/srtm3.html.

[11] Tarapues, V.M., Selección y aplicación de una metodología para la estimación de los factores de emisión de las fuentes móviles vehiculares de la ciudad de Bogotá. Research based on master's thesis, Universidad de los Andes: Bogotá, 2003. 